\title{
KRUNA WILANGAN BASA BALI KUNO SAJERONING KAMUS BASA BALI KUNO LAN PEPADANNYANE RING BASA BALI ANYAR
}

\author{
Km. Endy Suastika ${ }^{1}$, I Kt. Paramarta ${ }^{1}$, Ida Ayu Pt. Purnami ${ }^{2}$ \\ Program Studi Pendidikan Bahasa Bali, Fakultas Bahasa dan Seni \\ Universitas Pendidikan Ganesha \\ Singaraja, Indonesia \\ e-mail: \{suastikaendy@gmail.com, ketut.paramarta@undiksha.ac.id, \\ dayupurnamiku@yahoo.com\}@undiksha.ac.id
}

\begin{abstract}
Kuub
Tetilikan puniki matetujon mahbahang (1) soroh kruna wilangan sajeroning basa Bali Kuno, (2) pepadan kruna wilangan basa Bali Kuno ring basa Bali Anyar. Jejering tetilikan inggih punika prasasti Bali Kuno. Panandang tetilikan inggih punika kruna wilangan. Kramaning tetilikan sane kaanggen inggih punika kramaning dokumentasi. Data tureksa sane kaanggen minakadi mastikayang ceciren data, reduksi data, nyorohang data, miwah panyutetan. Pikolih tetilikan minakadi, (1) soroh kruna wilangan sajeroning basa Bali Kuno, sakadi kruna wilangan pokok tentu, kruna wilangan distributif, kruna wilangan kolektif, kruna wilangan pokok tak tentu, kruna wilangan klitik, kruna wilangan takehan (ukuran), miwah kruna wilangan pecahan, (2) pepadan kruna wilangan basa Bali Kuno ring basa Bali Anyar minakadi wangun miwah teges sane pateh, wangun mirib miwah teges sane pateh, lan wangun mabinayan miwah teges sane pateh.
\end{abstract}

Kruna Jejaton : basa bali anyar, basa bali kuno, kruna wilangan.

\begin{abstract}
Abstrak
Penelitian ini bertujuan menguraikan (1) jenis kata bilangan dalam bahasa Bali Kuno, (2) padanan kata bilangan bahasa Bali Kuno dalam bahasa Bali Anyar. Subjek penelitian adalah prasasti Bali Kuno. Objek penelitian adalah kata bilangan. Metode penelitian yang digunakan adalah metode dokumentasi. Analisis data yang digunakan seperti identifikasi data, reduksi data, klasifikasi data, dan kesimpulan. Hasil penelitian yaitu, (1) jenis kata bilangan dalam bahasa Bali Kuno seperti kata bilangan pokok tentu, kata bilangan distributif, kata bilangan kolektif, kata bilangan pokok tak tentu, kata bilangan klitik, kata bilangan ukuran, dan kata bilangan pecahan, (2) padanan kata bilangan basa Bali Kuno dalam basa Bali Anyar seperti bentuk dan makna yang sama, bentuk mirip dan makna yang sama, dan bentuk berbeda dan makna yang sama.
\end{abstract}

Kata Kunci ; bahasa bali baru, bahasa bali kuno, kata bilangan. 


\begin{abstract}
This study aims to describe (1) type of numbers in old Balinese, and (2) type of numbers in new Balinese. The subject of this study is the ancient Balinese inscription while the object is the numbers. The documentation method is used in order to collect the data. Then, the data analysis uses several techniques such as, data identification, data reduction, data classification, and data summarization. The result of this study was found that (1) type of the numbers in the old Balinese such as distributive numbers, collective numbers, indefinite distributive numbers, klitik numbers, measurement numbers, and fractional numbers, and (2) type of numbers in New Balinese which based on the same meanings, such as the equivalent forms, the similar forms, and the different forms.
\end{abstract}

Keywords:. new balinese, numbers, old balinese.

\section{PURWAKA}

Basa Bali wantah silih tunggil basa daerah sane wenten ring panegara Indonesia. Basa Bali taler kabaos basa ibu, santukan basa Bali kaanggen piranti mabebaosan olih krama Bali, minakadi bebaosan ring parikrama adat, agama, miwah bebaosan sarahina ring kulawarga. Kawentenan basa Bali mangkin sane kasengguh basa Bali Anyar sampun akeh keni ius panglimbak basa lianan. Ngenenin indik panglimbak basa punika kawastanin aab (periodisasi) panglimbak basa Bali. Bawa dkk (1985: 21) maosang, aab panglimbak basa Bali kakepah dados tigang soroh minakadi Basa Bali Kuno, Basa Bali Tengahan lan Basa Bali Anyar (modern). Maosang indik basa Bali Kuno, pastika nenten prasida lempas saking tetamian kaluhuran minakadi prasasti, utaminnyane sane kapanggihin ring Bali (Bawa dkk, 1985: 27). Kabaos kadi asapunika, santukan kawigunan basa Bali Kuno wantah prasida kapanggihin sajeroning prasasti. Prasasti punika wantah kaanggen genah nyurat sakancan budaya Bali, kahuripan lan tetamian kaluhuran. Punika mawinan ring prasasti Bali Kuno wenten tampak tetamian ngenenin indik kawentenan basa Bali Kuno. Ring basa Bali Kuno wenten soroh-soroh kruna minakadi kruna aran, kruna kria, kruna wilangan, kruna dwi lingga, taler wewehannyane minakadi pangater, seselan, miwah pangiring.

Kruna inggih punika pupulan suara (suara wiadin wianjana) sane madue arti. Nganutin wangsan krunanyane wenten dasa soroh inggih punika kruna aran, kruna kria, kruna kahanan, kruna wilangan, kruna pangarep, kruna panyambung, kruna pangentos, kruna katerangan, kruna sandang, miwah kruna pakeengan. Ring Tata Basa Bali Anyar (Kridalaksana sajeroning Antara, 1986: 49-118) wangsan kruna kakepah nganutin kahanan (sifat) miwah parisolah kruna punika sajeroning lengkara ngawinang wewangsan kruna punika kadadosang telulas, sakadi : kruna aran (nomina), kruna kria (verba), kruna kahanan (ajektiva), kruna adverbia (adverbia), kruna wilangan (numeralia), kruna pengentos (pronomina), kruna pitaken (interogativa), kruna panunjuk (demonstrativa), kruna sandang (artikula), kruna pangarep (preposisi), kruna panyambung (konjungsi), kruna fatis (kategori fatis), miwah kruna pakeengan (interjeksi).

Kruna wilangan inggih punika kruna sane kaanggen ngwilang wiadin kruna sane nyihnayang pawilangan, nyihnayang akeh, nyihnayang runtutan, nyihnayang galah, miwah nyihnayang utawi nyambatang nomor wiadin angka (Kentjono, 2010: 182). Kawentenan kruna wilangan sajeroning basa Bali Kuno punika mabuat pisan majeng ring krama lan iraga sareng sami, santukan akeh kawigunannyane sane kaanggen sarahina-rahina minakadi anggen nyihnayang pawilangan, lan nyihnayang angkepan. Kruna wilangan puniki kaanggen ngwantu ri kala wenten pikobet ngenenin indik angka utawi wilangan tur kalimbakang malih. Ring aab sakadi mangkin, kruna wilangan punika sampun sayan nglimbak, 
sakemaon yening cingak malih ring kahuripan dumun wantah kaanggen nyihnayang akeh utawi maketekan napi ja saluirnyane. Taler kruna wilangan pinaka simbol utawi pralambang sane kaanggen ri kala nyihnayang barang utawi benda.

Kruna wilangan ring Tata Sukerta Basa Bali kakepah dados kalih soroh inggih punika kruna wilangan wit-witan miwah kruna wilangan undagan (tingkatan) (Gautama, 2006: 49-51). Kapertama, ring kruna wilangan wit-witan wenten sane mabungkulan, upami sa, dua, telu, pat, lima, miwah salanturnyane. Sane marupa pahan (bagian), upami atenga, apah empatan, apah limaan, miwah sane siosan. Sane marupa takehan (takaran), upami abidang (sehelai), apasang (sepasang), abancang (sekuntum bunga), miwah sane siosan. Kaping kalih ring kruna wilangan undagan (tingkatan) inggih punika polih pangater "ka", upami kasa (kapertama), kadasa (kaping dasa). Sane ngangge "ping", upami ping pat, ping pindo.

Kruna wilangan ring Tata Basa Indonesia kakepah dados nem soroh inggih punika kruna wilangan bulat, kruna wilangan pahan (pecahan), kruna wilangan tingkat, kruna wilangan tan janten (tak tentu), kruna wilangan terikat, kruna wilangan papasten (himpunan) (Kentjono, 2010: 182). Tiosan ring punika kruna wilangan ring Tata Basa Inggris kakepah dados tigang soroh inggih punika kruna wilangan biasa (cardinal number), kruna wilangan bertingkat (ordinal number), miwah kruna wilangan pecahan (fraction) (Hariyanto, 2003: 62).

Sajeroning tetilikan indik Sintaksis Bahasa Bali Kuna dan Sejarah Perkembangannya nureksain panglimbak frasa basa Bali Kuno dados basa Bali Anyar (Sutjiati, 1990: 48). Yadiastun kruna wilangan basa Bali Kuno wenten kabaosang, nanging mapaiketan sareng kawigunan sajeroning frasa. Kruna wilangan basa Bali Kuno miwah sorohsorohnyane nenten pradata kabahbahang. Frasa nomina sane madue nomina inti nyarengin kruna basa Bali Kuno, taler ring frasa nomina basa Bali Anyar sane madue pawates nyarengin nomina inti punika. Kruna wilangan sajeroning basa Bali Kuno miwah basa Bali Anyar sering kawewehin pangiring -ng, minakadi ring basa Bali Kuno : kambing rukud 1 'kambing satu ekor', lan ring basa Bali Anyar, sakadi tikeh limang lembar 'tikar lima lembar'.

Sajeroning tetilikan indik Evolution Of Verbal Morphology in Balinese nureksain panglimbak tata pawangunan kruna basa Bali Kuno miwah basa Bali Anyar (Sutjiati, 1992: 307). Punika kauningang kruna wilangan basa Bali Kuno sane kawarisin ring basa bali standar, minakadi ha maartos siki, 'sebuah, seorang', jhang maartos makasami, jyesta maartos sasih kaping solas ring agama hindu. Yadiastun kruna wilangan takehan (numeral classifiers) kabaosang, nanging nenten nuek maosang indik kruna wilangan miwah pahpahannyane. Prasida kacutetang basa Bali Kuno ngicenin kontribusi leksikal sane mabuat pisan sajeroning basa Bali Anyar sane wenten ring aab sakadi mangkin, minakadi ring kruna basa Bali Kuno atak 'dua ratus', dados basa alus madya satak 'dua ratus'. Asapunika taler kruna basa Bali Kuno ha 'satu', dados basa alus madya a 'satu'.

Sihong Zhang (2014: 883) Numeral Classifiers in Ersu nilikin indik kruna wilangan takehan (numeral classifiers) basa Ersu ring Cina. Basa Ersu akeh madue wangsan kruna rumasuk kruna wilangan takehan kisaran (sortal classifiers), ngwilang (mensural classifiers), miwah nyihnayang galah (time classifiers). Tetilikan puniki wantah nuek maosang kruna wilangan takehan, taler panandangnyane sane mabinayan inggih punika basa Ersu. Nanging tetilikan sane katilikin olih panilik indik kruna wilangan sajeroning basa Bali Kuno miwah sorohsorohnyane.

Antoinette Schapper sareng Harald Hammarstrom Innovative Numerals in Malayo-Polynesian Languages outside of Oceania nilikin indik kruna wilangan inovatif basa Melayu-Pollinesia kasinahang sareng sub kelompok saking Oceanik. Pabinayan punika kadasarin antuk kruna wilangan inovatif sane ngawigunayang tata cara pawewehan (aditif), pakuangan (subtraktif), miwah perkalian (multiplikatif) (Galis, 1960: 424). Ring tetilikan puniki taler 
mengobservasi indik inovasi kruna wilangan komplek (complex numeral innovations) ring wewidangan kangin Indonesia sane nyihnayang iusan jadma saking Papua, sane kabuktiang ri kala mabebaosan. Tetilikan punika ngenenin indik kruna wilangan inovatif wantah nyihnayang indik basa Melayu-Pollinesia tur keni iusan basa.

Madasar antuk bahbahan dadalan pikobet ring ajeng, tetilikan kruna wilangan sajeroning basa Bali Kuno dahat mabuat pisan kalaksanayang. Madasar antuk tetimbangan punika, panilik nglaksanayang tetilikan sane mamurda "Kruna Wilangan Basa Bali Kuno sajeroning Kamus Basa Bali Kuno lan Pepadannyane ring Basa Bali Anyar".

Bantang pikobet tetilikan (1) napi manten soroh kruna wilangan sajeroning basa Bali Kuno?, (2) Sapunapi pepadan kruna wilangan basa Bali Kuno ring basa Bali Anyar?

Tetujon tetilikan puniki inggih punika (!) Mangda prasida mahbahang soroh kruna wilangan sajeroning basa Bali Kuno, (2) Mangda Prasida mahbahang pepadan kruna wilangan basa Bali Kuno ring basa Bali Anyar. Ri sajeroning tetilikan puniki wenten kawigunannyane, minakadi kawigunan pamucuk lan kawigunan panglimbak sane kabahbahang sakadi ring sor.

Kawigunan pamucuk (teoritis) saking pikolih tetilikan puniki inggih punika prasida ngicenin kaweruhan indik kruna wilangan sajeroning basa Bali Kuno. Kawigunan panglimbak (praktis) tetilikan puniki inggih punika (a) Majeng ring Pangwacen. Tetilikan puniki kaaptiang prasida kaanggen sasuluh sane mawiguna majeng ring para pangwacen utaminnyane majeng ring krama Bali mangda uning ngenenin indik kruna wilangan mabasa Bali Kuno, (b) Majeng ring Panilik Siosan, tetilikan puniki prasida kaanggen mulat wali nglimbakang tetilikan sane asoroh utawi sane mapaiketan sareng parikrama ngrereh kruna wilangan sajeroning basa Bali Kuno, (c) Majeng ring Mahasisia, Pikolih saking tetilikan puniki prasida kadadosang sarana anggen ngwewehin kaweruhan lan prasida ngwantu para mahasisia nguningin tur ngresepang indik kruna wilangan sajeroning basa Bali Kuno. (d) Majeng ring Panilik, tetilikan puniki prasida kaanggen pengalaman langsung sajeroning nguningin sapunapi kruna wilangan sajeroning basa Bali Kuno

\section{KRAMANING TETILIK}

Kramaning tetilik punika silih tunggil sane mautama ri kala nglaksanayang tetilikan. Pinaka tata cara sane kaanggen panilik sajeroning mupulang data tetilik (Sugiyono, 2012: 59). Dudonan sane kalaksanayang ri tatkala nyawis pikobet (Wendra, 2014: 31).

Manut panampen para sujana ring ajeng, prasida kacutetang kramaning tetilik sane kadadosang sepat siku-siku sajeroning tetilikan puniki inggih punika piranti, prosedur, lan cara sane kaanggen panilik nglaksanayang tetilikan (sajeroning mupulang data) mangda mikolihang pisaur ring bantang pikobet. Kramaning tetilik kakepah dados patpat inggih punika : (1) Pendekatan Ian Soroh Tetilikan, (2) Wit Data, (3) Parikrama Mupulang Data, (4) Data Tureksa.

Pendekatan lan soroh tetilikan sane kaanggen ring tetilikan puniki inggih punika deskriptif kualitatif, santukan matetujon mahbahang kruna wilangan sajeroning basa Bali Kuno. Lianan ring punika pendekatan deskriptif kualitatif kaanggen mangda ngamolihang data sane patut, becik, lan manut kadi kasujatian saking data sane katilikin. Jejering ring tetilikan puniki inggih punika prasasti basa Bali Kuno. Sane dados panandang ring tetilikan puniki inggih punika kruna wilangan.

Parikrama mupulang data sane kaanggen ring tetilikan puniki inggih punika kramaning dokumentasi. Sane kaping untat data tureksa sane kaanggen sajeroning tetilikan puniki inggih punika mastikayang ceciren data, reduksi data, nyorohang data, miwah panyutetan.

\section{PIKOLIH MIWAH TETEPASAN}

Ngenenin indik kruna wilangan, pinaka teori sane kapolihang miwah kaanggen ring tetilikan puniki akehnyane 8 soroh inggih punika 1) kruna wilangan 
pokok tentu, 2) kruna wilangan distributif, 3) kruna wilangan pokok tak tentu, 4) kruna wilangan klitik, 5) kruna wilangan takehan (ukuran), 6) kruna wilangan pecahan, 7) kruna wilangan pokok kolektif, miwah 8) kruna wilangan tingkat (Sulaga, 1996: 245251).

Kruna wilangan pokok tentu inggih punika kruna sane wangunnyane janten, upami nol, besik/sa, dua, telu, pat, lima, nem, pitu, kutus, sia (Sulaga, 1996: 245). Wenten pupulan parinama sane kapolihang ring tetilikan puniki indik kruna wilangan pokok tentu inggih punika marupa sikian, papuluhan, miwah panyatakan. Sane rumasuk sikian minakadi sa, ha, dua, dwa, tlu, pat, lima, pitu. Sane rumasuk papuluhan minakadi hapulu, dwang puluh. Taler sane rumasuk sajeroning panyatakan inggih punika kruna wilangan atak. Kapolihang 22 data sane marupa kruna wilangan pokok tentu. Saking tetilikan sane sampun kamargiang, kapolihang data kruna wilangan pokok tentu inggih punika sa, dua, tlu, patpat, pat, lalima, lima, pitu, tujuh, dasa, rua, ha, dwang, pañcami, dwa, dwang puluh, puluh, tiga, atak, tunggal, hapulu, duang. Wenten malih parinama indik kruna wilangan inggih punika sikian. Sane rumasuk sikian inggih punika sa, ha, tunggal 'satu'; dua, dwa, rua 'dua'; tlu, tiga 'tiga'; pat, patpat 'empat'; lima, lalima, pañcami 'lima'; miwah pitu, tujuh 'tujuh'. Ring tetilikan puniki sane manut saking prasasti basa Bali Kuno nenten kapolihang kruna wilangan sane nujuang teges 'enam', 'delapan', miwah 'sembilan'. Ring tetilikan puniki wantah kapolihang kruna așādha 'bulan ke dua belas' ring punggelan prasasti Trunjan B Illb.1.4. Taler kapolihang kruna sdawāra 'enam hari' ring Kamus Basa Bali Kuno-Indonesia (1984: 197). Durung prasida kajantenang napike teges sad/sda ring kruna așādha miwah sdawāra punika mateges 'enam', santukan data sane prasida nyinahang indike punika kantun kirang.

Salanturnyane parinama sane mateges 'delapan', taler nenten kapolihang sajeroning tetilikan puniki, wantah asiki data katarka kantun mapaiketan ring teges 'delapan' inggih punika kruna astakaya 'delapan badan'. Yening selehin malih, kruna asta sane wenten ring kruna astakaya, asta punika mateges 'delapan', nanging kruna sane janten berdiri sendiri nenten kapolihang. Wenten malih wilangan sane mateges 'sembilan' nenten kapolihang sajeroning prasasti Bali Kuno sane katilikin. Sane kapolihang wantah kruna nilanawa sane mateges 'sembilan warna biru'. Yening selehin malih kruna nawa sajeroning kruna nilanawa punika mateges 'sembilan', nanging kruna sane mateges 'sia' sane berdiri sendiri durung kapolihang. Kruna wilangan sane kapolihang miwah rumasuk papuluhan inggih punika hapulu, dwang puluh sane mateges 'dua puluh'. Taler sane rumasuk panyatakan inggih punika kruna wilangan atak 'dua ratus' kapanggihin sajeroning kruna tigangatak 'enam ratus' ring prasasti Sembiran All VIla.2. Sajeroning tetilikan puniki nenten kapolihang parinama sane mawangun atusan, ribuan, kantos ayutaan.

Kruna wilangan distributif prasida kawangun antuk tata cara ngwawanin kruna wilangan (Sulaga, 1996: 249). Artosnyane inggih punika (1) '... demi...', (2) 'masingmasing'. Imbanyane sakadi besik-besik 'satu-satu', dua-dua 'dua-dua', lima-lima 'lima-lima'. Kruna (se) tiap, tiap-tiap, miwah masing-masing, taler rumasuk kruna wilangan distributif. Kruna (se) tiap utawi tiap-tiap madue teges sane mirib sareng kruna masing-masing, nanging kruna masing-masing prasida berdiri-sendiri tan pakruna aran (nomina), yening (se) tiap miwah tiap-tiap punika mabinayan. Kapolihang 8 data sane marupa kruna wilangan distributif. Saking tetilikan sane sampun kamargiang, kapolihang data kruna wilangan pokok tentu inggih punika bilang, dug, babar, angkĕn, angkan, sing (asing), di, wilang. Sajeroning data sane kapolihang, wenten silih tunggil kruna sane wangunnyane mirib taler tegesnyane sane pateh, minakadi kruna bilang sareng wilang, miwah kruna angkan sareng angkěn. Kruna wilangan bilang sane mateges 'setiap', miwah kruna wilangan wilang taler mateges 'setiap' sajeroning basa Bali Kuno. Antuk punika sinah makakalih kruna punika mirib utawi akidik pisan wenten pabinayannyane, nanging tetep kasurat nuut salinan prasasti Goris (1954). 
Salanturnyane kruna wilangan angkan sane mateges 'setiap' miwah kruna wilangan angkěn taler mateges 'setiap'. Pateh sareng kruna bilang miwah wilang, makakalih kruna punika akidik sane wenten pabinayan yening cingak saking wangunnyane, nanging tegesnyane pateh. Kruna wilangan angkan miwah angkěn sane mateges 'setiap' kaanggen ri kala nyinahang silih tunggil parindikan sane wangun kaleketin antuk kruna aran (nomina) sane kasinahang miwah nenten kaanggen ring ungkur lengkara. Imbanyane sakadi angkan māgha 'setiap bulan Magha'. Taler kruna bilang miwah wilang sakadi punika kawigunannyane.

Kruna wilangan pokok tak tentu nuek indik akeh (jumlah) sane nenten janten, minakadi kruna wilangan liyu 'banyak', bedik 'sedikit', miwah makejang 'semua'. Kapolihang 28 data sane marupa kruna wilangan pokok tak tentu. Saking tetilikan sane sampun kamargiang, kapolihang data kruna wilangan pokok tak tentu inggih punika yathā, jhang, para, jěmĕk, jāng, paraspara, sawanda, makapasuk, kasamagrin, marang, halyiun, lyu, Iwir, samā, baya, kabeh, maranghadan, sāmya, maka-nāyaka, sa, paḍa, tangeh, sarbwa, jhāng, samuha, kapwa, yata, mulihakat. Sajeroning data sane kapolihang, wenten silih tunggil kruna sane wangunnyane mirib miwah tegesnyane sane pateh, minakadi kruna wilangan yathā, yata, jāng, jhang, jhāng. Kruna wilangan yathā miwah yata madue teges sane pateh inggih punika mateges 'semua, segala'. Makakalih krnna punika madue akidik pabinayan yening cingak saking wangun krunanyane, nanging tegesnyane pateh. Salanturnyane kruna wilangan jang, jhang, miwah jhāng madue teges sane pateh inggih punika mateges 'semua'. Wenten malih kruna lyu 'banyak' sajeroning basa Bali Kuno sane kapolihang ring tetilikan puniki. Taler Beratha (1992: 312) ngamolihang kruna lyu miwah lyur sane mateges many 'banyak'.

Kruna wilangan klitik sane wit krunanyane saking basa Jawa Kuno miwah ketah mawangun proklitik. Dadosnyane, kruna wilangan puniki kaleketang ring arep kruna aran (nomina) sane kaleketin. Sane rumasuk enklitik inggih punika nilanawa, taler sane rumasuk proklitik inggih punika astakaya, dasatanta, miwah pañcakala. Kapolihang 8 data sane marupa kruna wilangan klitik. Saking tetilikan sane sampun kamargiang, kapolihang data kruna wilangan klitik inggih punika habhagi, astakaya, dasatanta, pañcakala, habulan habulan, hatmuang hatmuang, nilanawa, miwah hatĕmwang hatěmwang. Antuk data punika wenten silih tunggil kruna wilangan sane rumasuk enklitik miwah proklitik. Enklitik inggih punika kruna wilangan sane magenah ring ungkur kruna aran sane ngleketin, yening proklitik inggih punika kruna wilangan sane magenah ring arep kruna aran sane kaleketin. Sane rumasuk enklitik inggih punika kruna nilanawa, taler sane rumasuk proklitik inggih punika astakaya, dasatanta, miwah pañcakala. Ring kruna wilangan pokok tentu sane nenten kapolihang data kruna wilangan 'delapan' sareng 'sembilan'. Kruna wilangan sane rumasuk enklitik inggih punika nilanawa 'sembilan warna biru'. Kruna wilangan sane rumasuk proklitik inggih punika astakaya 'delapan badan', dasatanta 'sepuluh orang', miwah kruna pañcakala 'lima waktu'. Kruna punika madue teges yening sampun kaleketin antuk kruna sane ngleketin utawi nenten prasida kruna punika berdiri sendiri.

Kruna wilangan takehan (ukuran) inggih punika kruna sane nyihnayang takehan, wenten sane mapaiketan sareng luas, lantang bawak, miwah akeh (jumlah), minakadi are, depa, ceeng. Taler kruna wilangan pecahan inggih punika kruna wilangan sane kakepah dados pahan sane lewih alit. Wantah kalih data sane kapolihang ring kruna wilangan takehan (ukuran) inggih punika batu miwah dpa. Taler kruna wilangan pecahan kapolihang wantah asiki. Kruna sane kapolihang inggih punika kruna batu 'bulih, abulih' kaanggen ri kala nyinahang akeh, sakadi tuah abatu buluanne mabuah. Yening kruna dpa 'ukuran panjang dari ujung ibu jari kaki sampai ujung jari tangan kanan yang direntangkan ke atas'. Kruna punika kaanggen ri kala nyinahang ukuran sane mapaiketan sareng napi sane kabaosang utawi kasinahang. Kruna tngah 'setengah' 
sajeroning kruna wilangan pecahan, kaanggen nyinahang kruna sane wenten pahan sane lewih alit. Wenten kruna sane kasengguh kruna penggolong sane kapolihang ring tetilikan puniki inggih punika kruna katih 'batang, sebatang' miwah rukud 'ekor, seekor'. Kruna punika kaanggen ri kala nyantenang parindikan kruna sane kaleketin, sakadi buron kaleketin antuk penggolong ukud, punyan-punyanan kaleketin antuk penggolong puun, miwah kertas olih penggolong lempir. Kruna tngah sane kapolihang ring tetilikan puniki, Beratha (1992: 316) taler ngamolihang kruna tngah sane mateges middle 'setengah'. Antuk punika sinah wenten parindikan sane pateh ngenenin indik kruna wilangan sane sida kapolihang sajeroning tetilikan.

Kruna wilangan pokok kolektif inggih punika kruna sane kawangun antuk ngwewehin wangun maka ring arep kruna wilangan miwah nganggen gugus kruna wilangan sane mapangiring -an. Minakadi maka telu, maka lima, satusan, selaean. Kruna wilangan tingkat inggih punika kruna sane kawangun antuk ngwewehin ka- ring arep wilangan sane kaiketin, upami kadua, katiga, kalima. Santukan kruna wilangan kolektif taler kawangun antuk paweweh ka-, makakalih soroh wangun kruna wilangan punika pateh. Prasida kapolihang pabinayannyane ri kala soang-soang kruna punika kaanggen. Kruna wilangan kolektif punika kagenahang ring arep kruna aran sane kasinahang, yening kruna wilangan tingkat kagenahang ring ungkur kruna aran sane kasinahang. Imba makakalih krunanyane sakadi puniki. Ring kruna wilangan kolektif inggih punika kruna kadua cawisan punika 'kedua jawaban itu' miwah yening kruna wilangan tingkat inggih punika kruna cawisan kadua punika 'jawaban kedua itu'. Wantah asiki sane kapolihang kruna wilangan pokok kolektif inggih punika kruna makalimang, miwah kruna wilangan tingkat kapolihang kalih data inggih punika çrawaṇa miwah māgha.

Sajeroning kruna wilangan pokok kolektif kapolihang kruna makalimang 'kelima-kelimanya'. Wantah amunika sane prasida kapolihang saking makudangkudang prasasti mabasa Bali Kuno ngenenin indik kruna wilangan pokok kolektif. Sajeroning kruna wilangan tingkat kapolihang kruna çrawaña mateges 'pertama, kesatu'. Kruna māgha mateges 'ke tujuh'. Ring kruna wilangan tingkat taler akidik kapolihang datanyane minakadi kruna sane mateges 'pertama, kesatu' miwah 'ke tujuh', nenten kapolihang data malih sakadi 'kedua, ketiga' miwah salanturnyane.

Pepadan kruna wilangan basa Bali Kuno ring basa Bali Anyar nuek maosang indik len raos (sinonim) basa Bali Kuno ring basa Bali Anyar. Sane kaanggen ngamolihang pepadannyane puniki inggih punika nganggen tata paiketan teges minakadi len raos (sinonim), polisemi, homonim, hiponim, miwah tungkalikan (antonim) (Djajasudarma, 1999: 36). Kapolihang 14 data pepadan kruna wilangan pantaraning basa Bali Kuno miwah basa Bali Anyar sane wangun lan tegesnyane pateh. Data saking pepadan kruna wilangan basa Bali Kuno ring basa Bali Anyar manut saking wangun miwah tegesnyane sane pateh inggih punika kruna bilang, dasa, dua, ha, kabeh, katih, lima, pat, pitu, puluh, rua, sa, tiga, miwah tunggal.

Kruna bilang sajeroning basa Bali Kuno sane madue pepadan bilang ring basa Bali Anyar. Makakalih kruna punika madue teges pateh inggih punika 'setiap' (Granoka, 1984: 56; Anom, 2014: 44). Salanturnyane kruna wilangan dasa sajeroning basa Bali Kuno sane madue pepadan dasa ring basa Bali Anyar. Makakalih kruna punika madue teges pateh inggih punika 'sepuluh'. Kruna wilangan dua sajeroning basa Bali Kuno sane madue pepadan dua ring basa Bali Anyar. Makakalih kruna punika madue teges pateh inggih punika 'dua'. Kruna wilangan ha sajeroning basa Bali Kuno sane madue pepadan ha ring basa Bali Anyar. Makakalih kruna punika madue teges pateh inggih punika 'satu'. Asapunika taler kruna wilangan kabeh sajeroning basa Bali Kuno sane madue pepadan kabeh ring basa Bali Anyar. Makakalih kruna punika madue teges pateh inggih punika 'semua, seluruh'. Kruna wilangan katih sajeroning basa Bali Kuno sane madue pepadan katih ring basa 
Bali Anyar. Makakalih kruna punika madue teges pateh inggih punika 'batang, sebatang'. Salanturnyane kruna wilangan lima sajeroning basa Bali Kuno sane madue pepadan lima ring basa Bali Anyar. Makakalih kruna punika madue teges pateh inggih punika 'lima'. Salanturnyane kruna wilangan pat sajeroning basa Bali Kuno sane madue pepadan pat ring basa Bali Anyar. Makakalih kruna punika madue teges pateh inggih punika 'empat'.

Kruna wilangan pitu sajeroning basa Bali Kuno sane madue pepadan pitu ring basa Bali Anyar. Makakalih kruna punika madue teges pateh inggih punika 'tujuh'. Salanturnyane kruna wilangan puluh sajeroning basa Bali Kuno sane madue pepadan puluh ring basa Bali Anyar. Makakalih kruna punika madue teges pateh inggih punika 'sepuluh'. Salanturnyane kruna wilangan rua sajeroning basa Bali Kuno sane madue pepadan rua ring basa Bali Anyar. Makakalih kruna punika madue teges pateh inggih punika 'dua'. Salanturnyane kruna wilangan sa sajeroning basa Bali Kuno sane madue pepadan sa ring basa Bali Anyar. Makakalih kruna punika madue teges pateh inggih punika 'satu'. Salanturnyane kruna wilangan tiga sajeroning basa Bali Kuno sane madu pepadan tiga ring basa Bali Anyar. Makakalih kruna punika madue teges pateh inggih punika 'tiga'. Sane kapinguntat inggih punika kruna wilangan tunggal sajeroning basa Bali Kuno sane madue pepadan tunggal ring basa Bali Anyar. Makakalih kruna punika madue teges pateh inggih punika 'satu'. Sajeroning kruna wilangan sane sampun kabahbahang punika prasida kacutetang inggih punika madue wangun miwah teges sane pateh santukan pepadannyane pantaraning basa Bali Kuno miwah basa Bali Anyar taler pateh utawi nenten wenten pauwahan kruna.

Sane kaping kalih indik pepadan kruna wilangan pantaraning basa Bali Kuno miwah basa Bali Anyar sane wangun mirib miwah tegesnyane pateh kapolihang 19 data. Datanyane inggih punika kruna wilangan atak, dpa, dua, dwa, jāng, jhang, jhāng, Iwir, lyu, pañcami, pat, rua, rukud, samā, samya, sarbwa, tlu, tngah, miwah wilang. Kruna atak sajeroning basa Bali Kuno sane madue pepadan satak ring basa Bali Anyar. Makakalih kruna punika madue teges pateh inggih punika 'dua ratus', nanging wenten pauwahan wangun krunanyane antuk paweweh inggihan punika atak dados satak. Beratha (1992: 307) taler ngamolihang kruna atak sane mateges two hundred 'dua ratus'. Kruna salanturnyane inggih punika kruna dpa sajeroning basa Bali Kuno sane madue pepadan depa ring basa Bali Anyar. Makakalih kruna punika madue teges pateh inggih punika 'ukuran panjang dari ujung ibu jari kaki sampai ujung jari tangan kanan yang direntangkan ke atas', nanging wenten pauwahan wangun krunanyane antuk paweweh inggihan punika dpa dados depa.

Asapunika taler kruna dua sajeroning basa Bali Kuno sane madue pepadan dwi, rua ring basa Bali Anyar. Makakalih kruna punika madue teges pateh inggih punika 'dua', nanging wenten pauwahan wangun krunanyane antuk ngentosin silih tunggil aksara (huruf) inggihan punika dua dados dwi, rua. Salanturnyane inggih punika kruna dwa sajeroning basa Bali Kuno sane madue pepadan dua, dwi, rua ring basa Bali Anyar. Makakalih kruna punika madue teges pateh inggih punika 'dua', nanging wenten pauwahan wangun krunanyane antuk ngentosin silih tunggil aksara inggihan punika dwa dados dua, dwi, rua. Salanturnyane kruna jāng sajeroning basa Bali Kuno sane madue pepadan makejang ring basa Bali Anyar. Makakalih kruna punika madue teges pateh inggih punika 'semua'. Kruna jāng, jhang, jhāng sajeroning basa Bali Kuno mateges 'semua', nanging yening ring basa Bali Anyar kruna jang punika mateges 'taruh', dadosnyane yening kruna jang kawewehin antuk kruna maka inggih punika dados kruna makejang, kruna punika wau prasida mateges 'semua'. Salanturnyane kruna sajeroning basa Bali Kuno sane madue pepadan makejang ring basa Bali Anyar. Makakalih kruna punika madue teges pateh inggih punika 'semua'. Salanturnyane inggih punika kruna Iwir sajeroning basa Bali Kuno sane madue pepadan luir ring 
basa Bali Anyar. Makakalih kruna punika madue teges pateh inggih punika 'seluruh, segala macam', nanging wenten pauwahan wangun krunanyane antuk ngentosin silih tunggil aksara inggihan punika Iwir dados luir. Salanturnyane kruna lyu sajeroning basa Bali Kuno sane madue pepadan liu ring basa Bali Anyar. Makakalih kruna punika madue teges pateh inggih punika 'banyak', nanging wenten pauwahan wangun krunanyane antuk ngentosin silih tunggil aksara inggihan punika lyu dados liu.

Asapunika taler kruna pañcami sajeroning basa Bali Kuno madue pepadan panca ring basa Bali Anyar. Makakalih kruna punika madue teges pateh inggih punika 'lima', nanging wenten pauwahan wangun krunanyane antuk ngicalang silih tunggil aksara inggihan punika pañcami dados panca. Kruna salanturnyane inggih punika kruna pat sajeroning basa Bali Kuno miwah kruna wilangan patpat pinaka pepadannyane ring basa Bali Anyar, taler teges kalih kruna punika inggih punika 'empat'. Sajeroning kruna wilangan punika wenten pauwahan wangun krunanyane antuk ngapingkalihang kruna inggihan punika pat dados patpat. Kruna salanturnyane inggih punika kruna rua sajeroning basa Bali Kuno miwah kruna wilangan dua pinaka pepadannyane ring basa Bali Anyar, taler teges kalih kruna punika inggih punika 'dua'. Sajeroning kruna wilangan punika wenten pauwahan wangun krunanyane antuk ngentosin silih tunggil aksara inggihan punika rua dados dua. Salanturnyane kruna rukud sajeroning basa Bali Kuno sane madue pepadan ukud ring basa Bali Anyar. Makakalih kruna punika madue teges pateh inggih punika 'ekor, seekor', nanging wenten pauwahan wangun krunanyane antuk ngicalang silih tunggil aksara inggihan punika rukud dados ukud. Salanturnyane kruna samā sajeroning basa Bali Kuno sane madue pepadan sami ring basa Bali Anyar. Makakalih kruna punika madue teges pateh inggih punika 'semua', nanging wenten pauwahan wangun krunanyane antuk ngentosin silih tunggil aksara inggihan punika samā dados sami.
Kruna salanturnyane kruna sāmya sajeroning basa Bali Kuno sane madue pepadan sami ring basa Bali Anyar. Makakalih kruna punika madue teges pateh inggih punika 'semua', nanging wenten pauwahan wangun krunanyane antuk ngentosin silih tunggil aksara inggihan punika sāmya dados sami. Salanturnyane kruna sarbwa sajeroning basa Bali Kuno sane madue pepadan sarwa ring basa Bali Anyar. Makakalih kruna punika madue teges pateh inggih punika 'serba, segala', nanging wenten pauwahan wangun krunanyane antuk ngentosin silih tunggil aksara inggihan punika sarbwa dados sarwa. Salanturnyane kruna tlu sajeroning basa Bali Kuno sane madue pepadan telu ring basa Bali Anyar. Makakalih kruna punika madue teges pateh inggih punika 'tiga', nanging wenten pauwahan wangun krunanyane antuk ngentosin silih tunggil aksara inggihan punika tlu dados telu. Kruna tngah sajeroning basa Bali Kuno sane madue pepadan tenga, tengah ring basa Bali Anyar. Makakalih kruna punika madue teges pateh inggih punika 'setengah', nanging wenten pauwahan wangun krunanyane antuk ngwewehin silih tunggil aksara inggihan punika tngah dados tenga, tengah. Kruna sane kaping untat inggih punika kruna wilang sajeroning basa Bali Kuno sane madue pepadan bilang ring basa Bali Anyar. Makakalih kruna punika madue teges pateh inggih punika 'setiap', nanging wenten pauwahan wangun krunanyane antuk ngentosin silih tunggil aksara inggihan punika wilang dados bilang. $\mathrm{Ri}$ sajeroning pepadan kruna wilangan basa Bali Kuno ring basa Bali Anyar sane kabahbahang punika kapolihang wenten silih tunggil pauwahan aksara (huruf), pangicalan, paweweh, miwah ngapingkalihang kruna.

Sane kaping tiga indik pepadan kruna wilangan pantaraning basa Bali Kuno miwah basa Bali Anyar marupa wangun mabinayan miwah tegesnyane pateh utawi kasengguh len raos (sinonim) kapolihang 49 data. Datanyane inggih punika kruna wilangan angkan, angkĕn, babar, batu, baya, bilang, çrawaṇa, dasa, dua, dug, dwa, ha, habhagi, hatĕmwang, hatmuang, jāng, jĕmĕk, jhang, jhāng, kabeh, kapwa, 
kasamagrin, lima, lyu, māgha, makanāyaka, makapasuk, marang, mulihakat, pada, pañcami, para, paraspara, pat, pitu, puluh, rua, sa, samā, samuha, sāmya, sawanda, sing (asing), tangeh, tiga, tlu, tujuh, tunggal, yata.

Kruna wilangan sane kapolihang punika nyinahang wenten pabinayan wangun kruna luire saking basa Bali Kuno miwah basa Bali Anyar, nanging tegesnyane pateh utawi marupa wangun len raos (sinonim). Silih tunggil imba krunanyane inggih punika dwa ring basa Bali Kuno sane madue pepadan kalih ring basa Bali Anyar. Makakalih kruna punika mateges 'dua'. Kruna jěměk ring basa Bali Kuno sane madue pepadan agemel ring basa Bali Anyar. Makakalih kruna punika mateges 'segenggam penuh'. Beratha (1992: 310) taler ngamolihang kruna jĕmĕk ring basa Bali Kuno sane mateges a handful 'segenggam'. Taler kruna pat ring basa Bali Kuno sane madue pepadan catur ring basa Bali Anyar. Makakalih kruna punika mateges 'empat'. Kruna punika sinah wenten pepadan pantaraning basa, santukan wangun sane mabinayan nanging tegesnyane pateh. Antuk punika kawentenan basa Bali sampun akeh keni ius panglimbak basa.

\section{PAMUPUT}

Sajeroning ringkesan ring tetilikan puniki pacang mahbahang indik (1) bantang pikobet, (2) tetujon tetilikan, (3) kawigunan tetilikan, (4) teori sane kaanggen, (5) kramaning tetilikan miwah (6) pikolih tetilikan. Indike punika pacang kabahbahang ring sor.

Bantang pikobet ring tetilikan puniki inggih punika soroh kruna wilangan sajeroning basa Bali Kuno lan pepadan kruna wilangan basa Bali Kuno ring basa Bali Anyar. Tetujon tetilikan inggih punika mangda prasida mahbahang soroh kruna wilangan sajeroning basa Bali Kuno lan mangda prasida mahbahang pepadan kruna wilangan basa Bali Kuno ring basa Bali Anyar. Kawigunan tetilikan inggih punika kawigunan pamucuk (teoritis) sane madue kawigunan prasida ngicen kaweruhan indik kruna wilangan sajeroning basa Bali Kuno miwah kawigunan panglimbak (praktis) inggih punika majeng ring pangwacen, panilik siosan, mahasisia, miwah majeng ring panilik. Teori sane kaanggen inggih punika tata teges (semantik). Sajeroning tetilikan puniki inggih punika nganggen tetilikan deskriptif kualitatif miwah nganggen kramaning dokumentasi. Pikolih tetilikan inggih punika marupa soroh kruna wilangan sajeroning basa Bali Kuno lan pepadan kruna wilangan basa Bali Kuno ring basa Bali Anyar.

Saking pikolih miwah tetepasan sane sampun kabahbahang ring ajeng, prasida katingkesang soroh kruna wilangan sajeroning basa Bali Kuno kapolihang 74 data. Salanturnyane data punika kakepah dados kutus soroh inggih punika kruna wilangan pokok tentu, kruna wilangan pokok kolektif, kruna wilangan distributif, kruna wilangan pokok tak tentu, kruna wilangan klitik, kruna wilangan takehan (ukuran), kruna wilangan tingkat, miwah kruna wilangan pecahan. Data sane marupa kruna wilangan pokok tentu akehnyane 22 data, kruna wilangan pokok kolektif akehnyane wantah 1 data, kruna wilangan distributif akehnyane 8 data, soroh kruna wilangan pokok tak tentu akehnyane 28 data, kruna wilangan klitik akehnyane 8 data, kruna wilangan takehan (ukuran) akehnyane 2 data, kruna wilangan tingkat akehnyane 2 data, miwah kruna wilangan pecahan akehnyane wantah 1 data. Sajeroning Pepadan kruna wilangan basa Bali Kuno ring basa Bali Anyar kapolihang 82 data. Pepadan punika raris kasorohang dados tiga, inggih punika : kapertama pepadan kruna wilangan sane wangun miwah tegesnyane pateh, akehnyane 14 data; kaping kalih pepadan kruna wilangan sane wangun mirib miwah tegesnyane pateh, akehnyane 19 data; kaping tiga pepadan kruna wilangan sane madue wangun mabinayan miwah tegesnyane mirib utawi pateh (sinonim) akehnyane 49 data.

Malarapan antuk pikolih sane sampun kabahbahang, wenten piteketpiteket sakadi Majeng ring Guru miwah Dosen (tenaga pengajar) utamaning karya sastra ring kahuripan sane ngawinang sang sane ngajahin prasida nganggen karya sastra kadadosang silih tunggil pangajahan 
utawi piranti pangajahan anggen nelebin basa miwah kruna ring karya sastra punika. Majeng ring panilik lianan kaaptiang mangda prasida nglimbakang tetilikan puniki. Panglimbak sane kaaptiang inggih punika mangda nglaksanayang tetilikan sane asoroh, silih tunggilnyane ngenenin indik prasasti mabasa Bali Kuno. Indike punika kaaptiang kalaksanayang mangda wenten sandingan pikolih tetilikan sajeroning prasasti-prasasti basa Bali Kuno sane lianan salanturnyane.

\section{KAPUSTAKAAN}

Anom, I Gusti Ketut. 2014. Kamus BaliIndonesia Beraksara Latin dan Bali. Denpasar: Badan Pembina Bahasa Aksara dan Sastra Bali Provinsi Bali.

Antara, I Gede Nala, dkk. 2006. Tata Basa Bali. Denpasar: Dinas Kebudayaan Provinsi Bali.

Bawa, I Wayan, dkk. 1985. Studi Sejarah Bahasa Bali. Denpasar: Pemerintah Daerah Provinsi Daerah Tingkat I Bali.

dkk. 2002. Sejarah Perkembangan Bahasa Bali. Denpasar: Universitas Udayana.

Beratha, Ni Luh Sutjiati. 1992. "Evolution of Verbal Morphology in Balinese"

(thesis). Canberra: Australian Nation University.

2012. "Sintaksis Bahasa Bali Kuno dan Sejarah Perkembangannya". Jurnal Kajian Bali. Volume 2. Nomor 2 (kaca 69-86).
Djajasudarma, Fatimah. 1999. Semantik 1 Pengantar Ke Arah IImu Makna. Bandung: Refika Aditama.

Gautama, Wayan Budha. 2006. Tata Sukerta Basa Bali. Denpasar: Kayumas Agung.

Goris, Roelof. 1954. Prasasti Bali. Bandung: Lembaga Bahasa dan Budaja Universitet Indonesia.

Hariyanto, Dony. 2003. English Grammar for General Application. Surabaya: Gitamedia Press

Kentjono, Djoko. 2010. Tata Bahasa Acuan Bahasa Indonesia Untuk Penutur Asing. Jakarta: Penerbit Wedatama Widya Sastra.

Oka Granoka, dkk. 1985. Kamus Bahasa Bali Kuno-Indonesia. Denpasar: Proyek Pengembangan Bahasa dan Sastra Indonesia dan Daerah.

Schapper, Antoinette. 2013. "Innovative Numerals in Malayo-Polynesian Languages Outside of Ocenia". Leiden University.

Sulaga, I Nyoman, dkk. 1996. Tata Bahasa Baku Bahasa Bali. Denpasar: Pemerintah Provinsi Daerah Tingkat I Bali.

Wendra, I Wayan. 2014. Buku Ajar Penulisan Karya Ilmiah. Singaraja: UNDIKSHA.

Zhang, Sihong. 2014. "Numeral Classifiers in Ersu". Artikel Languange and Linguistics. Chinese: Anhui University of Chinese Medicin 